\title{
INFLUÊNCIA DO METAL DURO E DA GEOMETRIA DE FIEIRA NO DESGASTE DE FERRAMENTA DE TREFILAÇÃO DE FIOS DE LATÃO*
}

\author{
Gustavo Tressia ${ }^{1}$ \\ Leandro Almeida² \\ Victor Caso Moreira ${ }^{3}$
}

\section{Resumo}

Neste trabalho estudou-se a influência da classe do metal duro, sendo elas G30 e G20, utilizada para a fabricação de fieiras de trefilação de latão (ASTM C27000), na resistência ao desgate destas ferramentas. A geometria das ferramentas foi mantida a mesma, variando-se apenas o ângulo de entrada em 10, 13 e 15 graus, a fim de se observar alguma influência deste parâmetro. As ferramentas foram avaliadas após a tefilação de 10 toneladas de material. As superfícies de trabalho foram analisadas em Lupa Estereoscópica e Microscópio Eletrônica de Varredura, visando identificar os modos de desgaste predominantes. Em todas as fieiras foram observados riscos sendo estes mais intensos na fieira da classe G30. Em todas ferramentas também foi observado adesão de material trefilado, sendo que maiores quantidade de material aderido foram observadas também na fieira da classe G30. A ocorrência de maior quantidade de riscos foi associada a menor dureza da classe de metal duro e infere-se a menor vida útil desta ferramenta

Palavras-chave: Desgaste de Fieiras; Trefilação; Geometria da fieira; Latão.

\section{INFLUENCE OF THE CEMENTED CARBIDE CLASS AND GEOMETRY ON THE WEAR OF BRASS WIRE DRAWING DIES}

\section{Abstract}

The aim of this work was the evaluation of the effect of the cemented carbide class on the wear of brass wire drawing tool. The influence of tool geometry was also evaluated. The cemented carbides used in this study were commercial G20 and G30 classes and the variation of tool geometry was regarded to die angle (10,13 and 15 degrees). The working surfaces were analyzed using stereomicroscopy and scanning electron microscopy to identify the active wear mechanisms. All drawing dies presented scratches which were more intense in G30 tool. Brass adhesion was also observed in all drawing dies surfaces, notably in G30 tool. The more scratched surface observed in G30 tool was associated to the smaller hardness of that material. It's inferred smaller life cycles of drawing dies made of that material.

Keywords: Die wear; wire drawing; die geometry; brass.

1 Engenheiro Mecânico, Engenheiro de Processos na Paranapanema SA, Santo André, SP, Brasil.

2 Engenheiro Metalurgista, Engenheiro de Processos na Paranapanema SA, Santo André, SP, Brasil.

3 Engenheiro Metalurgista, Engenheiro de Desenvolvimento na Paranapanema SA, Santo André, $S P$, Brasil.

\footnotetext{
* Contribuição técnica ao $5^{\circ}$ Seminário de Trefilação: Arames, Barras e Tubos de Metais Ferrosos e Não Ferrosos, 24 e 25 de novembro de 2014, São Paulo, SP, Brasil.
} 


\section{INTRODUÇÃO}

O desgaste do ferramental na trefilação de fios é de suma importância para a produtividade e o custo do processo, bem como para a qualidade do material. Por exemplo, a variação na geometria da fieira pode resultar em desatendimento das tolerâncias especificadas ou até mesmo ruptura do fio por variação no estado de tensões ideal. As ferramentas empregadas geralmente são de metal duro (wídia), e podem se desgastar por diferentes mecanismos, nomeadamente abrasão e adesão. O entendimento das forças envolvidas no processo e do mecanismo de desgaste da ferramenta é essencial para a otimização dos parâmetros com ganhos de produtividade e qualidade.

Métodos analíticos e computacionais (elementos finitos) têm sido usados para estimar as forças e energias envolvidas no processo de trefilação. Como mostrado por Luis e Luri [1] em trabalho de comparação entre os diferentes métodos de análise, a geometria da ferramenta e o grau de redução influem de maneira crítica as tensões resultantes do processo. Para uma mesma redução, a energia para conformação do material aumenta com a abertura do ângulo de entrada da ferramenta, efeito oposto ao observado para a energia consumida pelo atrito. Estes dados mostram a existência de ângulo ideal para a zona de entrada, como previsto pelo Método do Limite Superior.Em trabalho de simulação numérica e experimentos com trefilação de cobre, Vega, Haddi e Imad [2] mostraram que o aumento do ângulo da zona de entrada implica maior força de trefilação e deformação mais heterogênea ao longo da seção do fio, considerando um coeficiente de atrito constante. Deve-se ter em mente que a faixa de ângulos estudada experimentalmente (14ำ a $\left.19^{\circ}\right)$ pode não ter abrangido a região de mínimo da força de trefilação.

A validação dos métodos computacionais passa pela determinação do coeficiente de atrito e sua relação com o ângulo de entrada da ferramenta. Nesse sentido, Felder e outros [3] propõem um método para determinação da tensão causada pelo atrito baseado em modelo termomecânico, cuja entrada é a força de trefilação e a temperatura na ferramenta, ambas as grandezas medidas. O método mostra-se promissor para avaliar a efetividade da lubrificação no processo de trefilação. Até o momento, no entanto, o método não foi aplicado para avaliação da influência da geometria da ferramenta sobre o atrito.

As tensões envolvidas mostram-se determinantes para o desgaste da fieira, como ilustra o recente trabalho de Lee, Lee e Kim [4] sobre trefilação do aço AISI 1010 com ferramenta de wídia. Os autores obtiveram como resultado (simulação e dados experimentais) o maior desgaste na região de maior tensão, próximo ao cilindro de calibração da ferramenta. Os autores também utilizaram o modelo do desgaste por abrasão de Archard e inserindo o efeito da vibração do fio na entrada da ferramenta. Com o modelo, foi possível prever a formação de anel na ferramenta, o qual se suspeita tenha tido origem em uma compressão cíclica na ferramenta, agravada pela vibração do fio, causando fadiga na superfície do material. Kim, Kim e Choi [5] também utilizaram o modelo proposto por Archard para predizer o desgaste de uma ferramenta de aço AISI D2 na trefilação de aço AISI 1010. Os autores mostraram boa adesão dos cálculos com os resultados experimentais, inclusive mostrando que o efeito do aquecimento do material é determinante para o desgaste. No entanto, os autores observaram que a região de maior desgaste da ferramenta não corresponde à região de maior esforço mecânico.

\footnotetext{
* Contribuição técnica ao $5^{\circ}$ Seminário de Trefilação: Arames, Barras e Tubos de Metais Ferrosos e Não Ferrosos, 24 e 25 de novembro de 2014, São Paulo, SP, Brasil.
} 
Em um ótimo trabalho sobre o desgaste de ferramenta de wídia na trefilação de aço recoberto com latão foi realizado por Hollinger, Depraetere e Giroux [6]. Embora com enfoque na influência do lubrificante, os autores mostraram a adesão de latão à ferramenta, principalmente quando utilizado o lubrificante com o qual se obteve o maior desgaste de ferramental. Segundo os resultados dos autores, o desgaste da wídia se dá por decoesão das partículas de WC após desgaste/fragilização da matriz de cobalto, efeito agravado com o aumento da temperatura de processo. Lu e outros [7] mostraram que a corrosão da matriz de cobalto pode agir de forma sinérgica com as tensões no material para o desgaste de ferramentas com lubrificação a óleo. No entanto, consideramos que este efeito é eliminado quando utilizado lubrificante sólido, por não haver eletrólito disponível para a corrosão.

Tendo em vista a escassa literatura encontrada sobre o desgaste de ferramentas na trefilação, em especial quando utilizada lubrificação sólida, o objetivo deste trabalho é iniciar um estudo sistemático da influência do material e da geometria da ferramenta no seu desgaste durante a trefilação de latão, procurando identificar os mecanismos envolvidos.

\section{MATERIAIS E MÉTODOS}

Foram produzidas 3 fieiras utilizando as características apresentadas na Tabela 1. Duas classes comerciais de metal duro, G20 e G30, foram utilizadas neste trabalho. As classes de metal duro apresentam dureza Vickers 1250 e 1160 e fração volumétrica de ligante (matriz de cobalto) de $12 \%$ e $15 \%$, respectivamente. Ambas as classes apresentam tamanho médio das partículas de carboneto de tungstênio (WC) de 2,5 $\square \mathrm{m}$. A geometria das ferramentas foi sempre a mesma, à exceção do ângulo do cone de entrada, que assumiu os valores $\alpha=10^{\circ}, \alpha=13^{\circ}$ e $\alpha=15^{\circ}$. Todas as fieiras foram utilizadas para a produção de 10 toneladas de fio de latão binário, liga ASTM C27000, com 7,70 mm de diâmetro de saída e 9,80 mm de diâmetro de entrada (38\% de redução em área). A lubrificação foi feita utilizando lubrificante sólido em pó e o processo se deu a velocidade constante.

Tabela 1. Características das fieiras

\begin{tabular}{|c|c|c|c|c|}
\hline Fieira & Widia & $\begin{array}{c}\text { Angulo de } \\
\text { entrada }\end{array}$ & $\begin{array}{c}\text { Cilindro de } \\
\text { calibração }\end{array}$ & Diâmetro \\
\hline 1 & $\mathrm{G} 30$ & 10 & $2,50 \mathrm{~mm}$ & $7,70 \mathrm{~mm}$ \\
\hline 2 & $\mathrm{G} 20$ & 13 & $2,50 \mathrm{~mm}$ & $7,70 \mathrm{~mm}$ \\
\hline 3 & $\mathrm{G} 20$ & 15 & $2,50 \mathrm{~mm}$ & $7,70 \mathrm{~mm}$ \\
\hline
\end{tabular}

As ferramentas foram fabricadas mediante eletroerosão a fio com posterior polimento manual utilizando pó de diamante com granulometria de 20/40 microns e para o polimento final com granulometria de 1/5 microns.

A cada tonelada produzida, foi retirada uma amostra de aproximadamente 1 metro para a realização de 10 medições de diâmetro e de excentricidade por meio micrômetro digital. Foi realizado acompanhamento de corrente elétrica no inicio e no final do processo.

Visando garantir que as matérias primas utilizadas para cada ferramental fossem similares, as mesmas foram fabricadas utilizando três fieiras novas com o mesmo material e mesma geometria, ou seja, o material semi-pronto a ser trefilado por cada

\footnotetext{
* Contribuição técnica ao $5^{\circ}$ Seminário de Trefilação: Arames, Barras e Tubos de Metais Ferrosos e Não Ferrosos, 24 e 25 de novembro de 2014, São Paulo, SP, Brasil.
} 
fieira estudada apresentava o mesmo dimensional. O material semi-pronto ainda passou por recozimento e decapagem em meio ácido.

Após a trefilação, as superfícies de trabalho das fieiras foram analisadas em Microscópio Eletrônico de Varredura (MEV) Joel JSM - 6010LA. Para análise das imagens obtida no MEV foi utilizado o software Image $\mathrm{J}$, permitindo realizar medições de comprimento. As superfícies de trabalho também foram analisadas em Lupa Estereoscópica.

\section{RESULTADOS E DISCUSSÃO}

\subsection{Análise Dimensional do Material Trefilado}

$\mathrm{Na}$ Tabela 2 são apresentadas as variações dimensionais máximas encontradas em função de cada ferramenta utilizada, bem como a variação percentual para cada caso. Observa-se que a variação dimensional dos materiais trefilados foi muito próxima para as 3 fieiras.

Tabela 2. Variação dimensional apresentada por cada fieira

\begin{tabular}{|c|c|c|}
\hline Fieira & $\begin{array}{c}\text { Variação } \\
\text { Máxima [mm] }\end{array}$ & $\begin{array}{c}\text { Variação } \\
\text { Máxima [\%] }\end{array}$ \\
\hline $\begin{array}{c}1-\text { G30 - } \\
10\end{array}$ & 0,016 & 0,21 \\
\hline $\begin{array}{c}2-\mathrm{G} 20- \\
13\end{array}$ & 0,017 & 0,22 \\
\hline $\begin{array}{c}3-\mathrm{G} 20- \\
15\end{array}$ & 0,014 & 0,18 \\
\hline
\end{tabular}

\subsection{Superfície de Trabalho - MEV}

Na Figura 1 e Figura 2 são apresentadas imagens obtidas em Microscópio Eletrônico e Varredura das superfícies de trabalho da Fieira 1 - G30 - 10 e da Fieira 2 - G20 - 13, escolhidas por serem as mais ilustrativas dos mecanismos de desgaste.

As imagens revelam uma clara diferença no mecanismo de desgaste das fieiras de classes diferentes de metal duro. Por meio do EDS realizado na superfície de trabalho foi possível confirmar a presença de material do fio trefilado, latão, aderido na superfície da ferramenta. Este comportamento foi também observado por Hollinger, Depraetere e Giroux em seu trabalho com fios de aço recobertos com latão [6]. Quanto às diferentes regiões da fieira, nota-se que a região do cilindro de calibração apresenta maior intensidade de adesão, quando comparada à entrada da ferramenta. Já quando comparadas as classes de metal duro, a Fieira 1 - G30 - 10 apresentou maior quantidade de adesão de latão do que a Fieira 2 - G20 - 13. Além disso, foi observada maior incidência de riscos na ferramenta da classe G30.

A fieira da classe G20 apresentou diversos pontos de vazio, sendo possivelmente devido ao arrancamento de carbonetos do material. Esse comportamento pode ter relação com a menor fração de matriz metálica nesta classe de metal e, portanto, menor tenacidade.

\footnotetext{
* Contribuição técnica ao $5^{\circ}$ Seminário de Trefilação: Arames, Barras e Tubos de Metais Ferrosos e Não Ferrosos, 24 e 25 de novembro de 2014, São Paulo, SP, Brasil.
} 
5 Seminário de Trefilação

Arames, Barras e Tubos de Metais

Ferrosos e Não Ferrosos

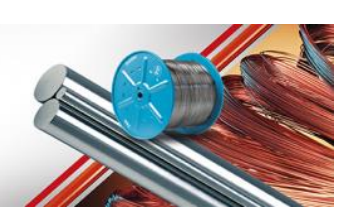

(a)
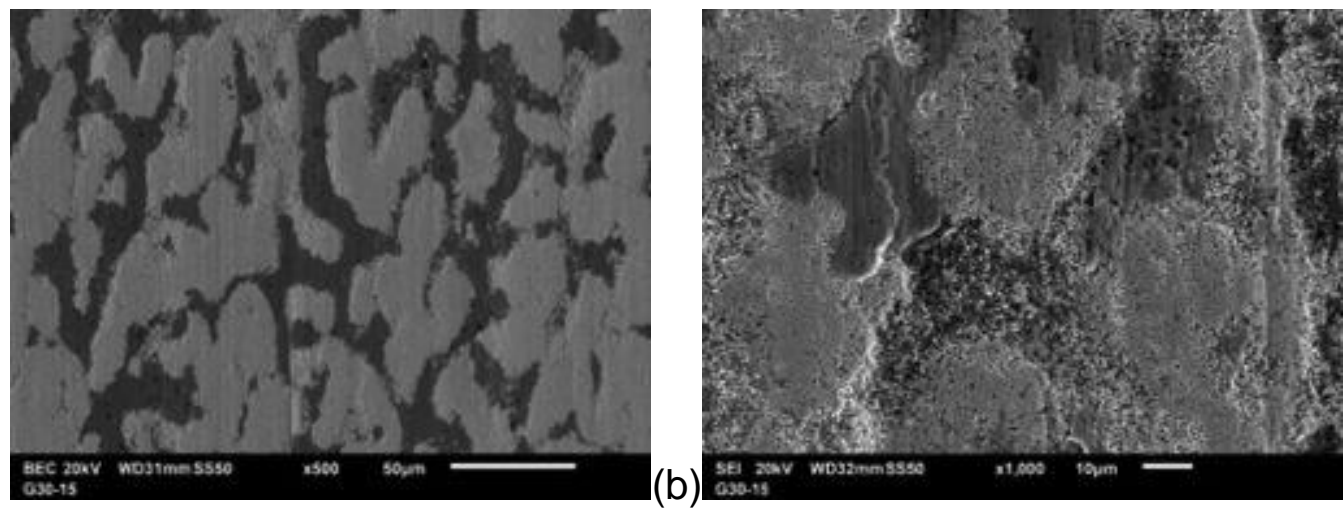

(c)

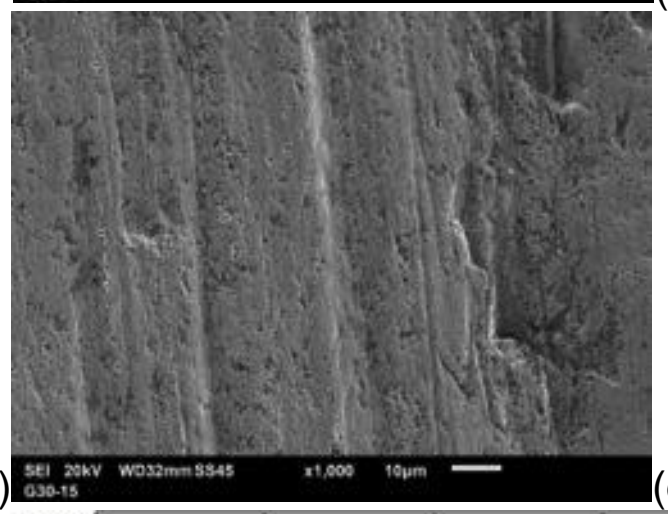

b)
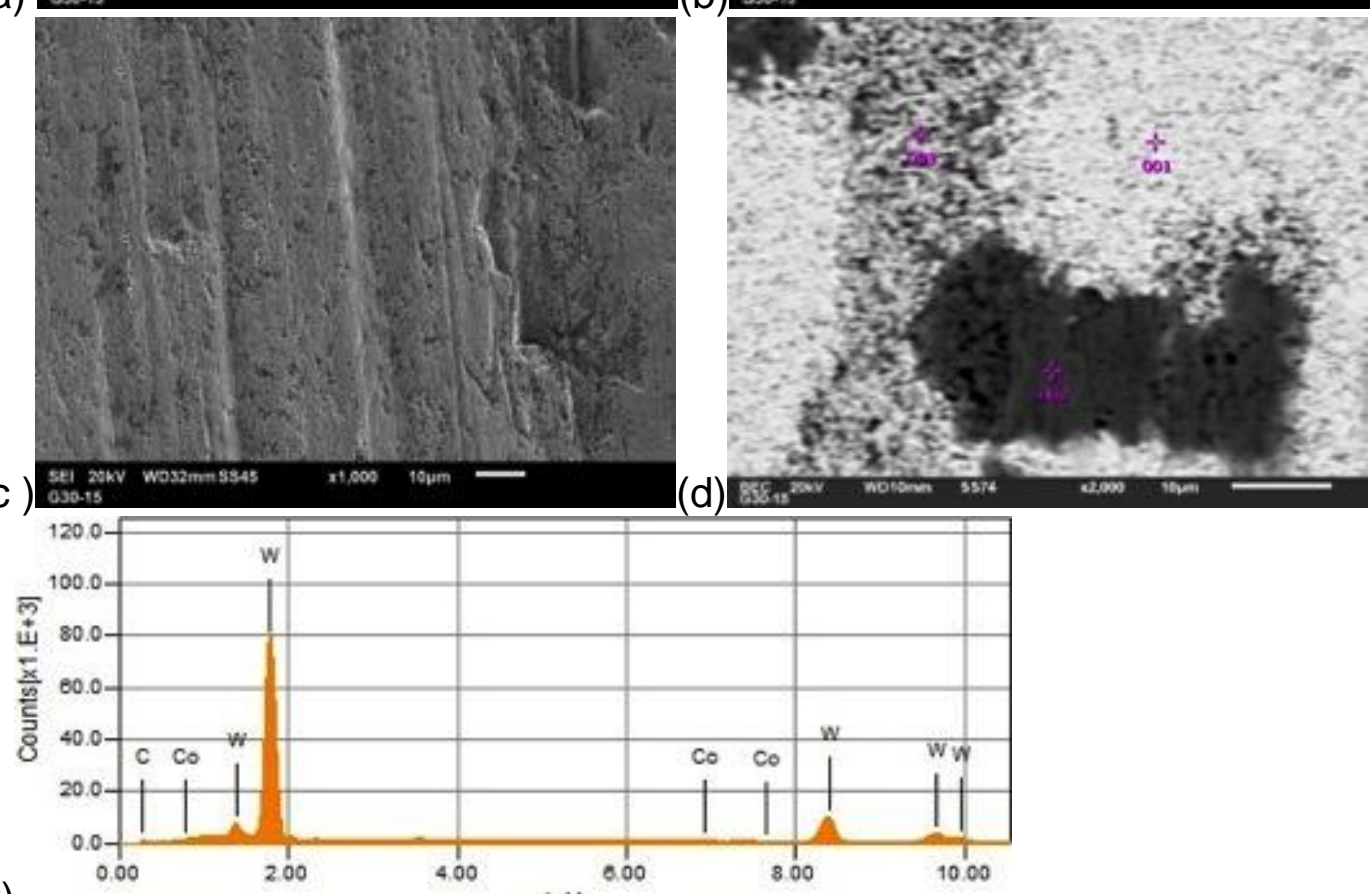

(f)

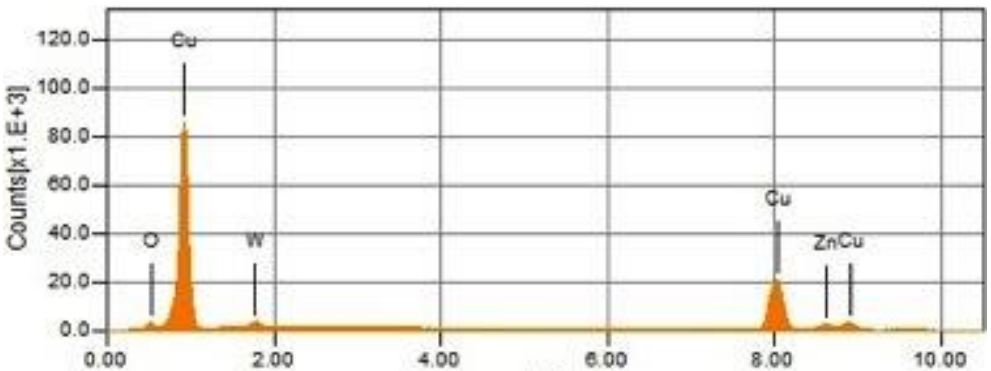

(g)

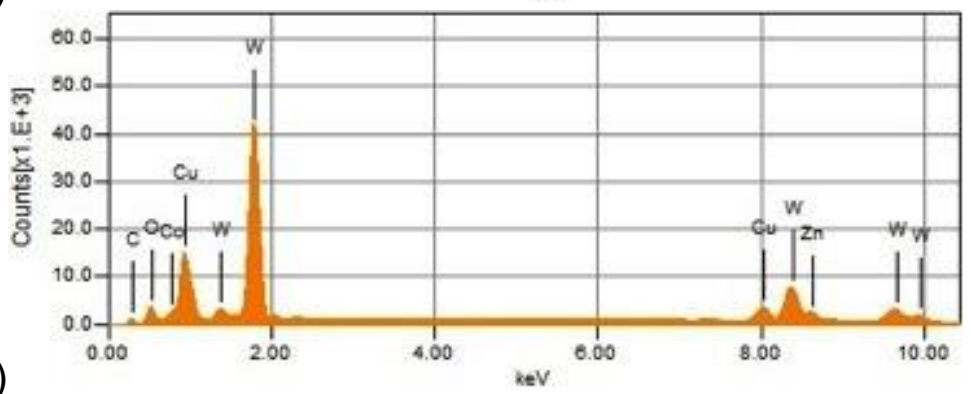

(h)

keV

Figura 1 - Superfície de trabalho da Fieira 1 - G30 - 10: (a) Cilindro de calibração com aumento de 500x, retorespalhado; (b) Cilindro de calibração com aumento de 1000X, elétrons secundários; (d) Riscos na região do cone de entrada,1000X; (e) Pontos de realização do EDS; (f) Ponto 1 do EDS; (g)Ponto 2 do EDS; (h) Ponto 3 do EDS

* Contribuição técnica ao $5^{\circ}$ Seminário de Trefilação: Arames, Barras e Tubos de Metais Ferrosos e Não Ferrosos, 24 e 25 de novembro de 2014, São Paulo, SP, Brasil. 
5 o Seminário de Trefilação

Arames, Barras e Tubos de Metais

Ferrosos e Não Ferrosos

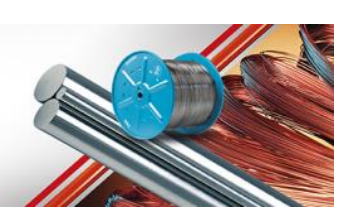

(a)

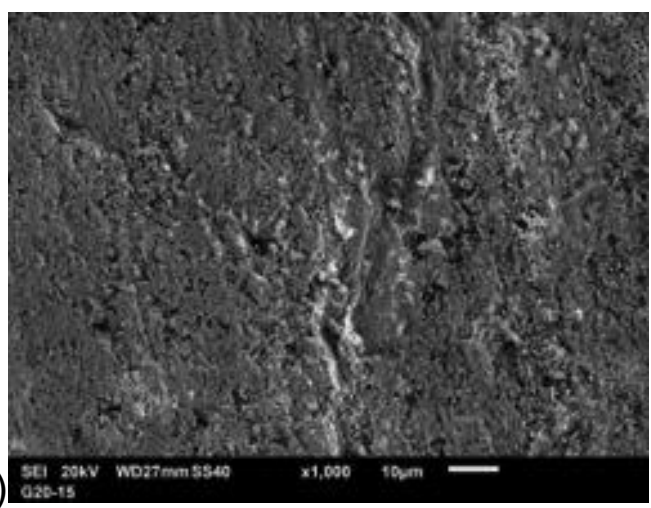

(b)

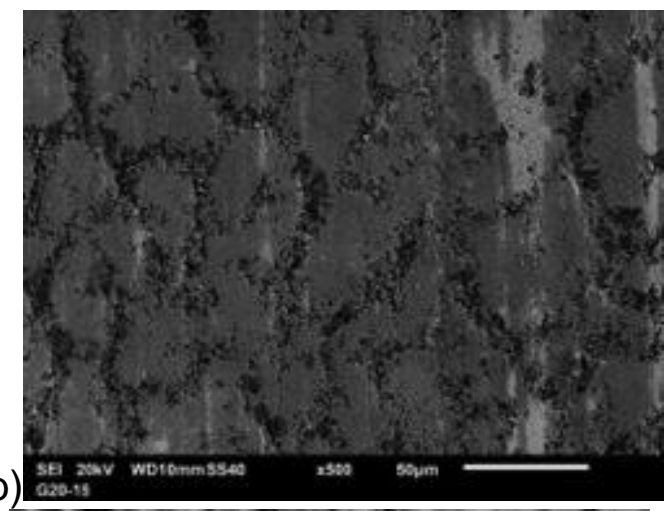

(c)
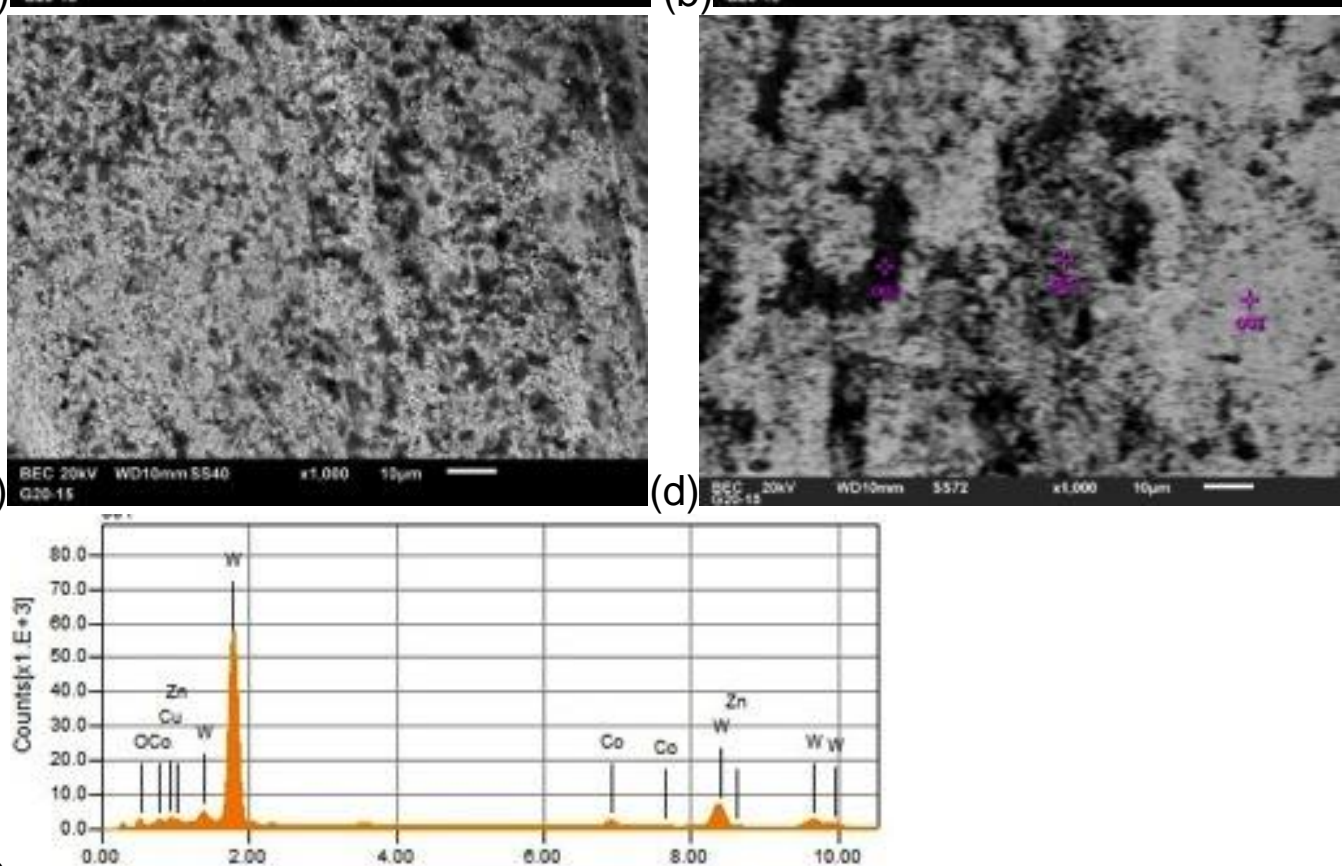

(d)

iev

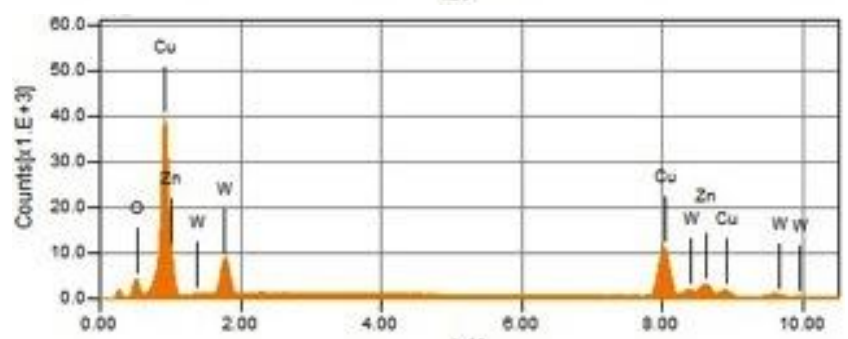

(e)

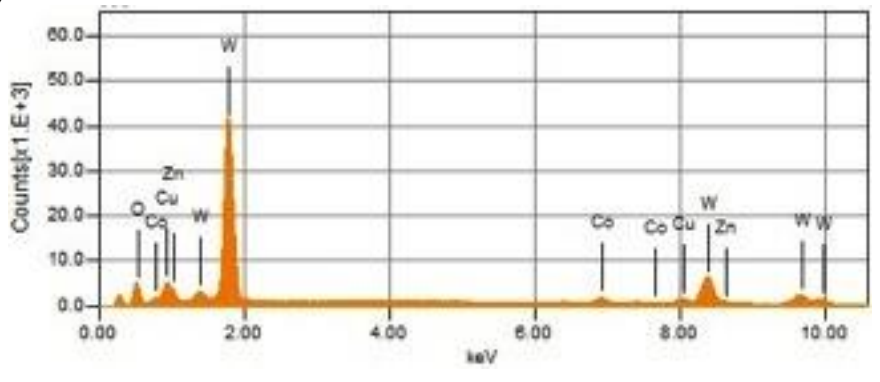

Figura 2. Superfície de trabalho da Fieira 2 - G20 - 13: (a) Riscos e arrancamentono cone de entrada com aumento de 1000x, elétrons secundários; (b) Cilindro de calibração com aumento de 500X, elétrons secundários; (c) Pontos de realizaçãoo EDS; (d) Ponto 1 do EDS; (e)Ponto 2 do EDS; (f) Ponto 3 do EDS 


\subsection{Superfície de Trabalho - Lupa Estereoscópica}

Na Figura 3 são apresentadas as imagens obtidas utilizando Lupa Estereoscópica da região entre o "anel" de adesão e o cilindro de calibração, sendo que as distâncias entre as duas regiões foram medidas utilizando software ImageJ, e os resultados são apresentados na Tabela 3. Nota-se que a distância de formação do "anel" de adesão em relação ao início do cilindro de calibração variou em função do ângulo de entrada da ferramenta, com a maior distância sendo encontrada para o menor ângulo de entrada (10\%) e a menor distância para o ângulo intermediário de $13^{\circ}$. Esse fenômeno não era esperado, pois se suponha que a região de formação do anel fosse a mesma do primeiro contato entre o fio e a ferramenta (a distância entre a primeira região de contato do trefilado e o cilindro de calibração aumenta com a diminuição do ângulo do cone de entrada).

Em comparação aos resultados de Lee, Lee e Kim [4], pode-se avaliar que a região mais propensa à fadiga da superfície, por compressão cíclica, não esteja exatamente sobre a primeira região de contato entre o fio e a ferramenta. Naquele trabalho, os autores observaram que a região de maior tensão aproxima-se do cilindro de calibração e que a vibração na entrada do fio acentua a ocorrência de anel.

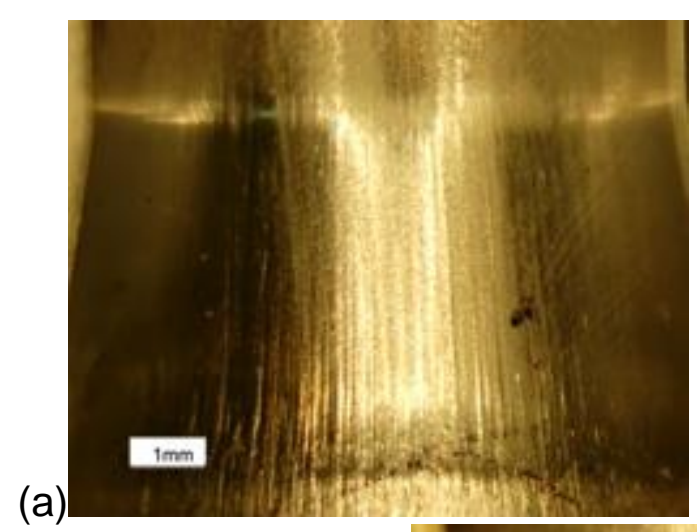

(b)
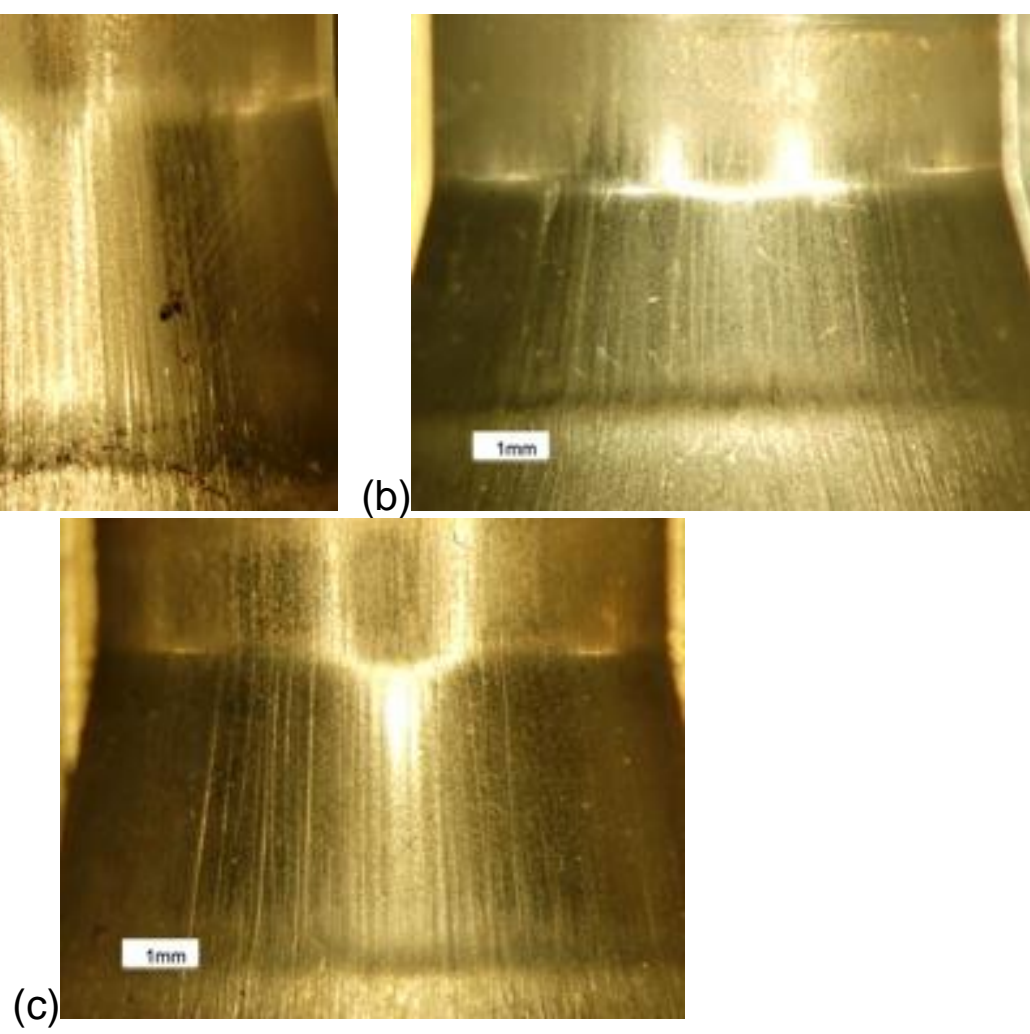

Figura 3. Região entre anel de adesão e zona de trabalho com aumento de 10X para: (a) Fieira 1 G30 - 10; (b) Fieira 2 - G20 - 13; (c) Fieira 3 - G20 - 15. 


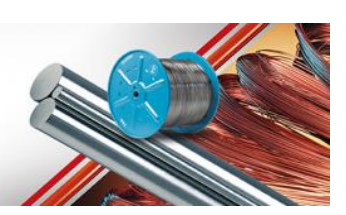

Tabela 3. Distância entre anel de adesão e zona de trabalho

\begin{tabular}{|c|c|}
\hline Fieira & $\begin{array}{c}\text { Distancia entre ZT e } \\
\text { Anel [mm] }\end{array}$ \\
\hline 1 - G30 - 10 & 5,26 \\
\hline 2 - G20 - 13 & 3,71 \\
\hline 3 - G20 - 15 & 4,56 \\
\hline
\end{tabular}

Ainda na Figura 4, Figura 5 e Figura 6 são apresentadas respectivamente imagens obtidas com Lupa Estereoscópica das regiões de entrada, do anel e da zona de trabalho, sendo possível observar maior presença de riscos na fieira da classe G30, Fieira 1 - G30 - 10, do que nas fieiras da classe G20 em todas regiões analisadas. Também se observa qualitativamente a formação mais intensa de anel nas ferramentas de metal duro classe G20.

(a)

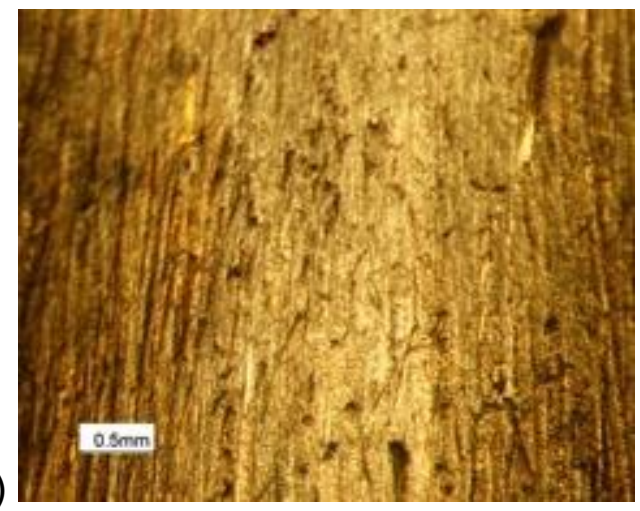

(b)
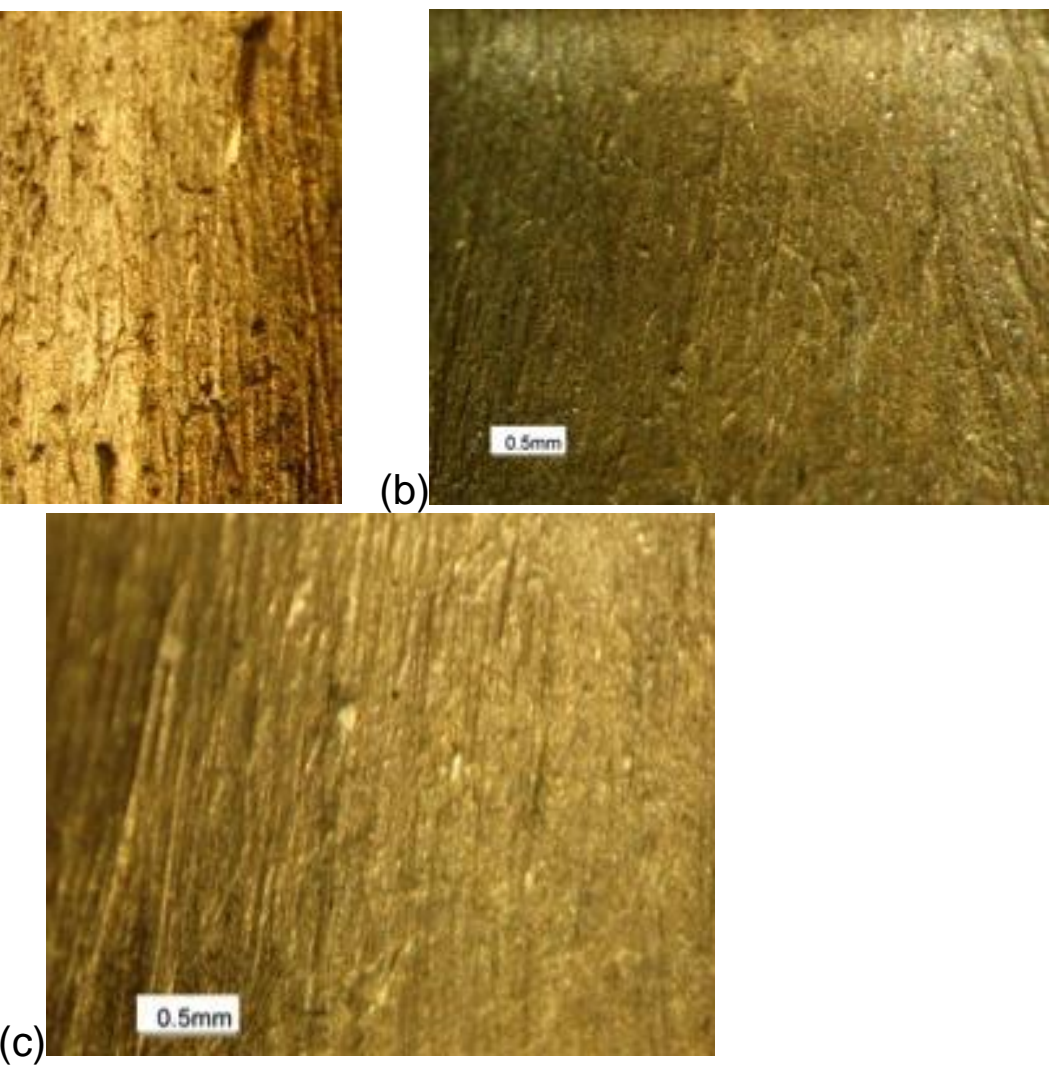

Figura 4. Região de entrada com aumento de 20x para: (a) Fieira 1 - G30 - 10; (b) Fieira 2 - G20 13; (c) Fieira 3 - G20 - 15 


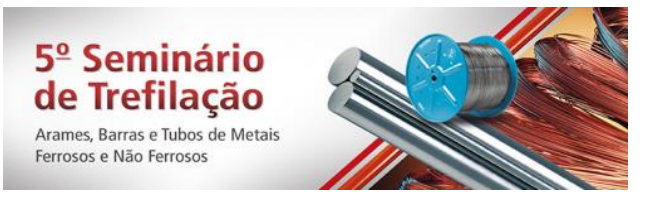

(a)

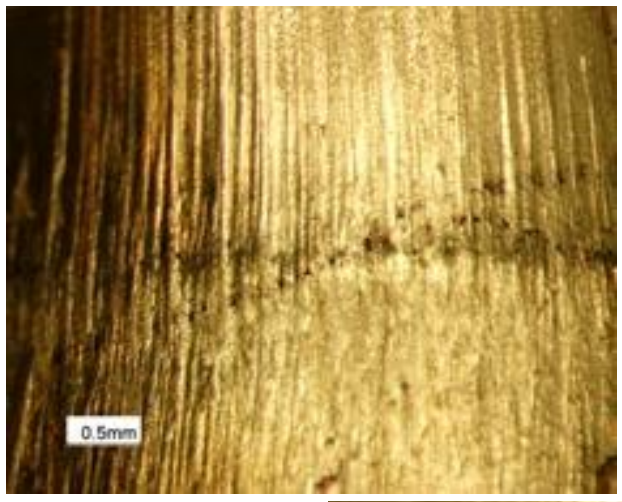

(b)
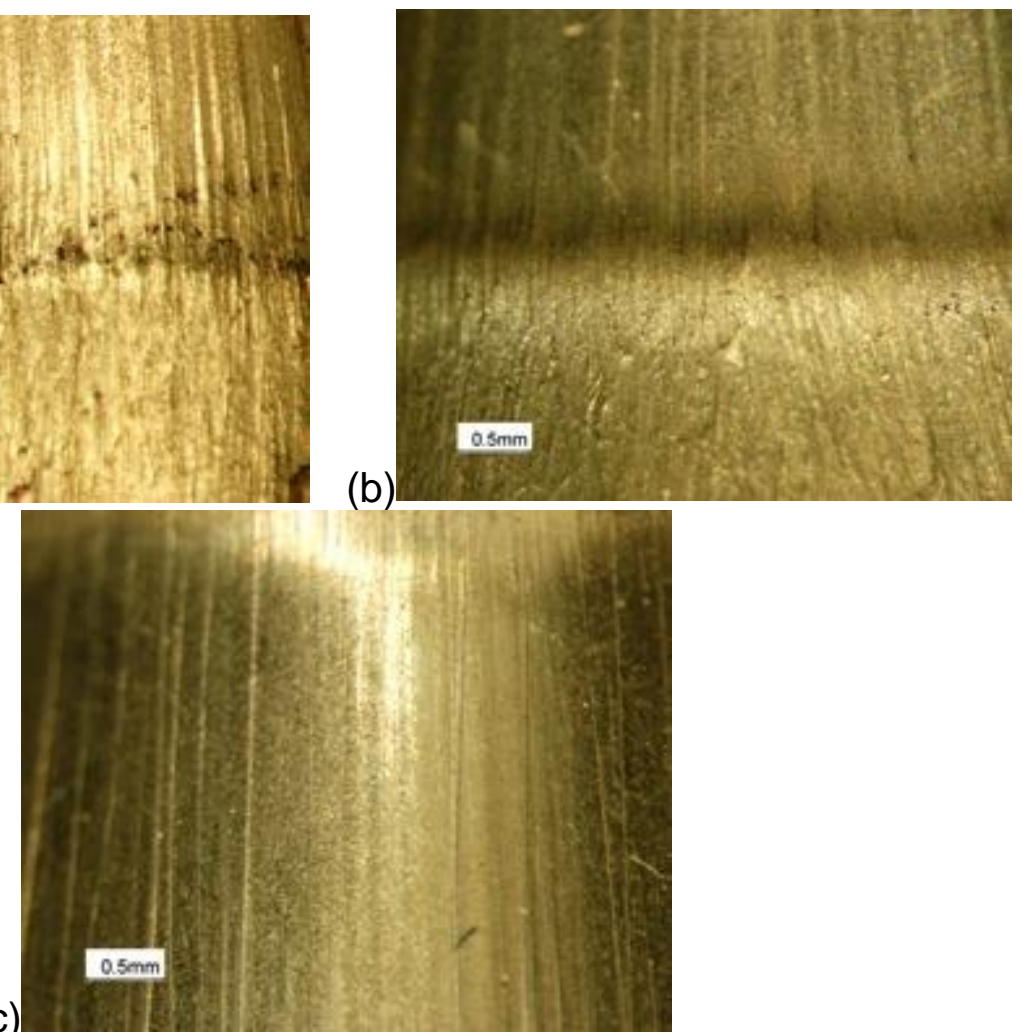

Figura 5. Região do anel com aumento de 20X para: (a) Fieira 1 - G30 - 10; (b) Fieira 2 - G20 - 13; (c) Fieira $3-$ G20 - 15

(a)
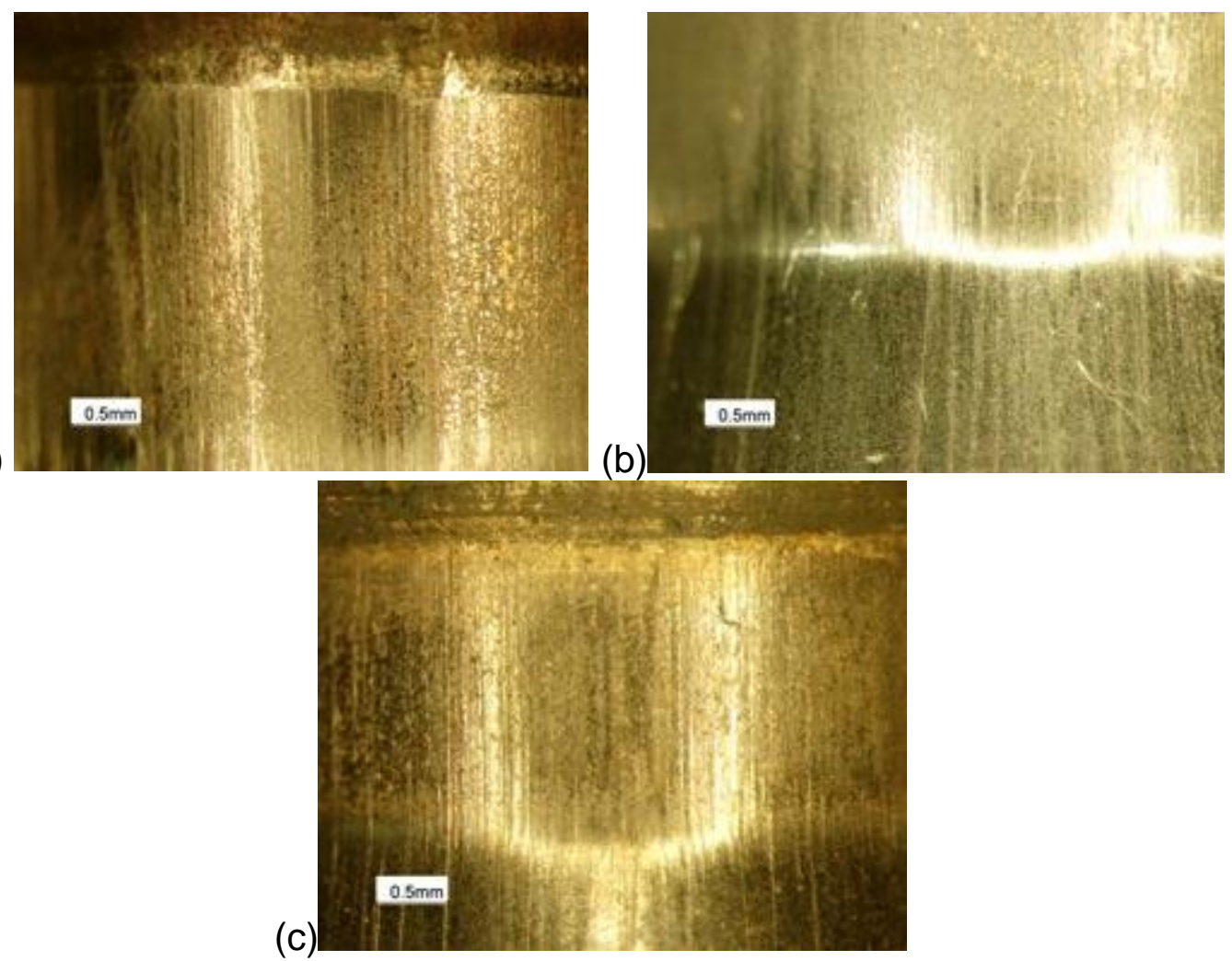

Figura 6. Região do cilindro de calibração com aumento de 20X para: (a) Fieira 1 - G30 - 10; (b) Fieira 2 - G20 - 13; (c) Fieira 3 - G20 - 15 
Em todas as fieiras foi possível observar riscos em todas regiões (entrada e cilindro de calibração) e também presença de superfície característica de adesão na região do cilindro de calibração.

A maior ocorrência de riscos na classe de fieira G30, quando comparada a G20, pode estar associada a menor dureza da classe G30, tendo em vista que quanto menor a dureza maior a facilidade de penetração de uma partícula dura, ou de uma aspereza, riscando o material.

Devido à maior quantidade de riscos e de adesão, pode-se inferir que a fieira de metal duro classe G30 apresentaria menor vida útil, pela necessidade de se retirar mais material no polimento da ferramenta. Esse resultado é semelhante ao encontrado em outros trabalhos que utilizam o modelo de Archard para prever o desgaste da ferramenta $[4,5]$. Esse modelo prevê o maior desgaste de um material com a diminuição de sua dureza. A tendência observada neste trabalho poderia ser constatada realizando-se o acompanhamento da ferramenta por um tempo maior de produção, quando submetida a polimento para adequação de sua superfície.

Tanto o mecanismo de desgaste como a variação dimensional dos fios trefilados não sugerem que o ângulo do cone de entrada influa consideravelmente no desgaste da ferramenta, na faixa estudada neste trabalho.

\section{CONCLUSÃO}

As medições de diâmetro realizadas no material trefilado não permitiram verificar a ocorrência de variações significativas entre as fieiras utilizadas. A caracterização das superfícies de trabalho das fieiras por meio das análises em MEV e Lupa Estereoscópica permitiu destacar dois tipos de mecanismos de desgaste, sendo eles abrasão, devidos aos riscos encontrados e adesão por meio do material do fio aderido na superfície, confirmado pelo EDS realizado. Na fieira fabricada utilizando a classe de metal duro G30 foi observado maior presença de material aderido e de riscos. A maior quantidade de riscos foi associada a menor dureza do material da classe G30 em relação a classe G20. Uma vez que as fieiras com maior quantidade de riscos necessitam ser submetida com maior frequência ao processo de polimento para a remoção dos mesmos, associou-se neste trabalho a dureza à resistência ao desgaste das fieiras, conforme modelo de Archard.

Nas três fieiras analisadas ocorreu formação do "anel" de adesão, sendo que a distância entre este e o cilindro de calibração não apresentou relação com o ângulo de entrada da ferramenta.

\section{Agradecimentos}

Os autores agradecem a Paranapanema S.A pelo apoio a pesquisa e por permitir o desenvolvimento de trabalhos como este. Agradecem também ao Laboratório de Fenômenos de Superfície da Universidade de São Paulo LFS-USP por disponibilizar o MEV e a Lupa Estereoscópica utilizados neste trabalho. 


\section{REFERÊNCIAS}

1 Luis CJ, León J, Luri R. Comparison between finite element method and analytical methods for studying wire drawing processes. Journal of Materials Processing Technology. 2005:164:1218-1225.

2 Veja G, Haddi A, Imad A. Investigation of process parameters effect on the copper-wire drawing. Materials and Design, 2009:30:3308-3312.

3 Felder E, Levrau C, Mantel M, Truong Dinh NG. Identification of the work of plastic deformation and the friction shear stress in wire drawing. Wear. 2012:286:27-34.

4 Lee SK, Lee SB, Kim BM. Process design of multi-stage wet wire drawing for improving the drawing speed for $0.72 \% \mathrm{C}$ steel wire. Journal of Materials Processing Technology, 2010. 210: 776-783.

$5 \mathrm{Kim}$ TH, Kim BM, Choi JC. Prediction of die wear in the wire-drawing process. Journal of Material Processing Technology, 1997. 65: 11-17.

6 Hollinger S, Depraetere E, Giroux O. Wear mechanism of tungsten carbide dies during wet drawing of steel tyre cords. Wear, 2003. 255: 1291-1299.

7 Lu R, Minarro L, Su YY, Shemenski RM. Failure mechanism of cemented tungsten carbide dies in wet drawing processo f steel cord filament. International Journal of Refractory Metals \& Hard Materials, 2008. 26:589-600. 